\title{
O processo de transnacionalização do judaísmo ortodoxo: um olhar antropológico sobre a expansão do movimento Chabad- Lubavitch
}

\section{The Process of Transnationalization in Orthodox Judaism: an anthropological view of the expansion of Chabad-Lubavitch Movement}

Marta Topel $^{1}$

\begin{abstract}
Resumo
No texto são analisados diferentes fenômenos que têm produzido transformações nas características no judaísmo ortodoxo, principalmente no movimento Chabad. Trata-se do processo de transnacionalização do Chabad em particular e do judaísmo de modo geral, do aumento exponencial das comunidades ortodoxas e das tentativas de reterritorialização da diáspora judaica com o decorrente deslocamento de Jerusalém como axis mundi.
\end{abstract}

Palavras-chave: Judaísmo ortodoxo. Transnacionalização. Chabad.

\begin{abstract}
The paper focuses in different phenomena which have produced relevant transformations in Orthodox Judaism, especially in the Chabad Movement. The main topics analyzed are the transnationalization process of Chabad in particular, and of Judaism in general, the exponential increase of Jewish Orthodox communities, and the attempts of re-territorialization of the Jewish Diaspora as a result of the displacement of Jerusalem as an axis mundi.
\end{abstract}

Key-Words: Orthodox Judaism. Transnationalization. Chabad.

\section{Introdução}

No documentário God Shabbos Vietnam², o espectador desprevenido fica surpreso, no mínimo, com as primeiras imagens: milhares de chassidim - trajados de preto como é o costume - reunidos em um imenso auditório cantam e dançam,

\footnotetext{
1 Possui graduação em Facultad de Sociología - Universidad de Buenos Aires (1985), mestrado em Sociologia e Antropologia Social - The Hebrew University Of Jerusalem (1990), doutorado em Ciências Sociais pela Universidade Estadual de Campinas (1996) e pós-doutorado - The Hebrew University in Jerusalem (2004-5).Atualmente é ms-5 da Universidade de São Paulo. Tem experiência na área de Antropologia, com ênfase em Cultura Judaica, atuando principalmente nos seguintes temas: judaísmo, antropologia, religião, identidade étnica e etnicidade. E-mail: mftopel@usp.br.

${ }^{2}$ DVD produzido pelo canal 8 da TV israelense, escrito e dirigido por Ido e Yael Sand.
} 
quase em transe, loas a seu líder, o sétimo Rebe de Lubavitch. Enquanto isso, o Rebe, sentado em uma cadeira alta, ancião e doente, olha para eles, sério. A cena transcorre em Nova lorque, na sede do Movimento Chabad-Lubavitch, mais precisamente no 770 Eastern Parkway, residência do Rebe e lugar de peregrinações, inclusive, depois da sua morte. Imediatamente a câmera nos leva a outro canto do planeta: Israel. Ali, mais modestamente, uma dezena de ortodoxos judeus, homens e mulheres, celebram em uma casa o que pareceria ser um grande acontecimento. A alegria é muita. Poucos minutos depois, uma mulher ortodoxa nos vinte anos de sua vida, entre homens que carregam móveis e encaixotam utensílios, explica qual é o motivo da celebração: ela, seu marido e seu filho de nove meses estão se preparando para ir ao Vietnam. "Ao Vietnam?", pergunta o cineasta. "Sim", responde a mulher enfaticamente, e a câmera já está posicionada em outra cena, na qual o casal explica com alegria - até com grande animação - o motivo da viagem: cumprir com uma missão que o Rebe de Lubavitch lhes impôs: fazer retornar judeus perdidos, isto é, judeus seculares, às verdadeiras raízes do judaísmo, tornando-os ortodoxos. Mas há judeus no Vietnam? O casal ri e responde afirmativamente, esclarecendo que há algumas dezenas de judeus que se afincaram nesse país, turistas israelenses que viajam ao Oriente e alguns executivos israelenses que vão e voltam do Vietnam a Israel com frequência. A missão do casal, um jovem casal de shluchim ${ }^{3}$ do Rebe de Lubavitch, é construir uma comunidade judaica em Hanói.

O objetivo deste trabalho é analisar o processo de transnacionalização do movimento ortodoxo judaico Chabad-Lubavitch. Nascido na Rússia a finais do século XIX e transplantado aos Estados Unidos na década de 1940, esse pequeno grupo chassídico (judaísmo ortodoxo com componentes místicos), a partir da década de 1990, logrou transformar-se em um império transnacional com filiais em todos os continentes. Além do mais, seu proselitismo, agressivo entre judeus seculares e liberais, tem sido uma das causas de seu crescimento e radicalização, mudando, em algumas comunidades, como a comunidade judaica paulistana, o judaísmo praticado pela maioria de seus membros.

No trabalho pretendo descrever brevemente o fenômeno do crescimento em âmbito global do movimento Chabad, colocando a ênfase nas suas estratégias de divulgação da doutrina que Ihe é característica, através do envio de emissários

\footnotetext{
${ }^{3}$ Do hebraico: emissários.
}

Cad. de Pesq. Interdisc. em Ci-s. Hum-s., Florianópolis, v.13, n.103, p.79-91, ago/dez 2012 
devidamente preparados a "todos os cantos do planeta", da construção de redes virtuais e sites nos quais seus rabinos predicam a necessidade dos judeus modernos transformarem-se em religiosos para acelerar a vinda do Messias.

\section{2 "Queremos o Messias agora!"”, ou da cristalização do movimento Chabad}

São muitas as interrogações que a globalização coloca, tanto se abordada como fenômeno a ser descrito e compreendido, ou como uma ferramenta metodológica para refletir sobre a realidade social contemporânea. Seus fluxos e refluxos e sua influência na configuração de novas formas de organização social são múltiplos, apesar de não contarmos com um panorama certeiro de como se estruturará - ou desestruturará - a vida social e a diversificação cultural num mundo completamente globalizado. Mas se as certezas são poucas, apesar de muitos os profetas que nos tentam convencer de tal ou qual caminho apresentado como irreversível, algumas tendências já podem ser esboçadas.

Assim, se bem é certo que os primeiros ecos do movimento de teshuvá ${ }^{5}$ se deixaram ouvir nos Estados Unidos na década de 1970, parece-me útil levar em consideração as características apontadas por Castells (1999), para o que ele definiu de "comunas culturais", isto é, comunidades surgidas no final desse milênio, cuja identidade é, basicamente, uma identidade de "resistência". No seu sentido mais amplo, a consolidação do renascer ortodoxo judaico nas décadas posteriores à sua origem, seja em Israel, nos Estados Unidos ou no Brasil, revela as tipicidades apontadas por Castells.

Entretanto, acredito importante assinalar que 0 processo de transnacionalização ou de rediasporização do judaísmo, como alguns preferem denominá-lo, nem sempre desemboca em tendências híbridas, abertas à mestiçagem cultural ou à criação de culturas de fronteiras. Muito pelo contrário, o que se observa em algumas regiões do mundo é o fenômeno oposto: o encapsulamento em universos simbólicos que, como assinala Pace (1997, p. 32): "permitem continuar imaginando unida, coerente e compacta, uma realidade social profundamente diferenciada e fragmentada". Grosso modo, esta é a realidade do

\footnotetext{
${ }^{4}$ Frase entonada em forma de cântico pelos adeptos do Chabad.

${ }^{5}$ Do hebraico: retorno. 
judaísmo que, nas últimas três décadas, tem observado um crescimento exponencial de suas correntes ortodoxas e fundamentalistas, tanto em Israel quanto nas diferentes diásporas, articulando intrincadas inter-relações entre os diferentes centros e suas respectivas periferias. Poder-se-ia acrescentar, ainda, que o aumento da população ortodoxa judia fora de Israel obedece principalmente à adesão de novos membros e não a um incremento do índice de natalidade entre esses grupos. Esse fenômeno, conhecido em hebraico como teshuvá (retorno de judeus laicos ao judaísmo ortodoxo) remonta às décadas de 1970 e 1980 para cristalizar-se e expandir-se nas décadas posteriores.

Contudo, é importante salientar alguns dados históricos que foram decisivos na criação do movimento de teshuvá no seio do judaísmo. Assim, as primeiras expressões do movimento de teshuvá contemporâneo remontam à pessoa do sexto Rebe da dinastia Chabad-Lubavitch, Rabino Yossef Yitzhak Schneerson que, perante os horrores, a devastação e a impotência sofridas pelo povo judeu durante o Holocausto, redefiniu em termos místico-apocalípticos o sentido de uma realidade histórica aparentemente irracional. Assim, na década de 1940, já nos Estados Unidos $^{6}$, o sexto e penúltimo Rebe da dinastia Lubavitch foi dentre os poucos rabinos que, com ousadia e coragem, perante o sentimento de fragilidade que se instalou nas comunidades judaicas com a expansão do Terceiro Reich, ofereceu uma resposta teológica, substituindo a impotência disseminada entre as comunidades judaicas por uma certeza escatológica e por um objetivo messiânico. Essa nova visão de mundo foi marcada por uma reconstrução apocalíptica da catástrofe, uma vez que o Rebe não hesitou em afirmar que a Alemanha de Hitler era a culminação de um plano cósmico de tribulações pré-messiânicas que, necessariamente, precipitariam e impeliriam a redenção Divina (ELIOR, 1998). Foi com discursos e homilias que o sexto Rebe de Lubavitch construiu uma interpretação dos acontecimentos, nos quais

a morte existencial e o presente sem esperança foram transfigurados num
nascimento espiritual e num futuro promissor, enquanto o tormento sem
sentido e a impotência foram transformados nas dores de parto messiânicas
- tudo culminando no nascimento místico de um novo futuro para o povo
judeu e para a terra de Israel. O rabino Yosef Yitzhak foi capaz de adiantar-
se, de forma elusiva, sobre uma conhecida concepção dialética talmúdica

${ }^{6}$ O movimento Chabad originou-se na Rússia no século XVIII. Na década de 1940, como resultado das perseguições sofridas, seu líder emigra para os Estados Unidos, onde rearticula a instituição que crescerá substantivamente nas décadas seguintes.

Cad. de Pesq. Interdisc. em Ci-s. Hum-s., Florianópolis, v.13, n.103, p.79-91, ago/dez 2012 
de redenção, que sugere que o Messias nasceu no dia em que o primeiro templo fora destruído. Esta concepção relaciona, inerentemente, a crise de uma catástrofe histórica e de um profundo sentimento de impotência à esperança na redenção e na onipotência messiânica (ELIOR, 1998, s/p).

Dessa forma, a ideia de teshuvá, na sua acepção moderna, nasce como resultado da conexão criada pelo Rabino Yossef Yitzhak entre a desaparição física da juderia europeia e a pobreza espiritual do judaísmo norte-americano ${ }^{7}$.

Se foram esses os termos em que a Segunda Guerra foi interpretada pelo Rabino Yossef Yitzhak, como bem assinala Elior (1998), o confronto com a realidade do Holocausto ou, mais especificamente, a desilusão pelo fracasso da profecia messiânica do Rebe, segundo a qual o plano Divino salvaria as vidas dos judeus da Europa, não abalou o Movimento ${ }^{8}$. Muito pelo contrário, o Chabad cresceu e ganhou adeptos como resultado da redefinição da profecia original pela necessidade de renovação espiritual do povo judeu como passo necessário para o advento do Messias. Desta perspectiva, se a tragédia do Holocausto confrontou o judaísmo com a destruição física de milhares de comunidades judaicas, a crescente assimilação dos judeus norte-americanos e de outros países à sociedade moderna, com a consequente perda do repertório cultural e religioso, foi percebida pelo Rabino Yossef Yitzhak como um Holocausto espiritual, realidade sobre a qual não só existia a possibilidade, mas o dever de exercer uma ação, no sentido de revertê-la e, com isso, acelerar os tempos da Era Messiânica.

Foi, então, a redefinição da profecia messiânica nesses termos que deu origem a um novo fenômeno dentro do judaísmo, que só cresceria nas décadas posteriores: o fato de uma corrente ortodoxa carregar sobre seus ombros a responsabilidade pelo destino do judaísmo e das comunidades judaicas como um todo.

O alcance planetário da missão imposta aos adeptos do Chabad pelo Rabino Yossef Yitzhak, e com mais ímpeto e sucesso ainda pelo genro, o sétimo Rebe de Lubavitch, Rabino Menachem Mendel Schneerson, não pareceu amedrontar sua concretização e, a partir da década de 1950, emissários do Movimento Chabad

\footnotetext{
${ }^{7}$ Para uma análise mais detalhada do posicionamento do sexto Rebe de Lubavitch, cf. Elior, 1998 e Topel, 2005.

8 Diversas pesquisas revelaram que os movimentos messiânicos não só não desmoronam ao confrontar-se com uma realidade diferente da profetizada por seus líderes, mas que sobrevivem e se fortalecem (FESTINGER; RIECKEN e SCHACHTER, 1964).
}

Cad. de Pesq. Interdisc. em Ci-s. Hum-s., Florianópolis, v.13, n.103, p.79-91, ago/dez 2012 
começaram a ser enviados a comunidades judaicas do mundo inteiro, com a missão de aproximar judeus laicos do judaísmo ortodoxo, mostrando-lhes o caminho da teshuvá.

No que diz respeito aos dias de hoje, segundo dados de Fishkoff (2003), só nos Estados Unidos o número de emissários e suas famílias chega a 30.000 , sendo que no restante do mundo os números apontam entre 80.000 e 100.000 .

\section{Estratégias no recrutamento de novos membros e a criação de um movimento transnacional}

Obviamente, para criar um império de tamanhas dimensões, o movimento Chabad colocou em prática uma série de estratégias que foram se sofisticando e diversificando-se com o passar dos anos. Assim, hoje o movimento mantém instituições em mais de 1000 cidades no mundo, em 70 países que oferecem educação formal e informal para todos os judeus interessados em aproximar-se do judaísmo ou aprofundar seus conhecimentos da religião judaica. Entre essas instituições se destacam novas sinagogas construídas pelos emissários, bem como academias de estudos rabínicos, centros de confraternização, entre outros.

As formas de aproximar novos membros da ortodoxia judaica diferem segundo o contexto considerado; todavia, observamos alguns padrões recorrentes quando o fenômeno ocorre fora de Israel. Em Israel, entretanto, como consequência da maioria da população ser judia, há certas semelhanças com as formas de proselitismo cristãs, a exemplo da abordagem de transeuntes na via pública, em universidades e espaços com grande concentração de pessoas, e a difusão da mensagem religiosa pela rádio e TV.

Em meu livro Jerusalém \& São Paulo: a nova ortodoxia judaica em cena, no qual analiso o movimento de teshuvá na cidade de São Paulo, destaquei que em Israel dito movimento ganha ímpeto na década de 1970, principalmente após a vitória inesperada do Estado de Israel na Guerra dos Seis Dias, com a decorrente conquista dos lugares santos do judaísmo. O que parecia incrível - a esmagadora vitória do Estado de Israel diante dos cinco países que o atacaram - foi traduzida por diferentes setores religiosos da sociedade israelense como um milagre. Diante desses acontecimentos, o sétimo Rebe de Lubavitch urgiu seus emissários a atuar com maior ímpeto e estabeleceu várias instituições do movimento em Israel. A 
recuperação de lugares bíblicos como Jerusalém e Hebron foi uma vitória militar que o Rebe não hesitou em transformar como sua, asseverando que foi o trabalho de seus emissários, dos verdadeiros soldados judeus entre judeus não observantes e seu retorno ao judaísmo o que provocou a derrota dos países árabes. Como assinalam Heilman \& Friedman (2010, p. 189): "Ele [o Rebe] quis que a Guerra dos Seis Dias fosse uma vitória judaica dos Lubavitch, um milagre baseado nas mitzvot ", , e isto, na cosmovisão do movimento, implicava nem mais nem menos que a aceleração na chegada do Messias.

$\mathrm{Na}$ diáspora, as estratégias de recrutamento de novos membros são diferentes, dado que se trata de contextos nos quais os judeus são minoria e o judaísmo não tem como missão converter gentios. Basicamente, o padrão é o seguinte: emissários do Chabad chegam ao destino imposto a eles pelo Rebe, tentam se conectar às instituições judaicas já existentes e, caso elas não existam, procuram os judeus que moram nessa cidade e os convidam a passar as festas do calendário judaico junto a eles. Fishkoff (2003, p. 209) conta em detalhe como foi realizada pela primeira vez a celebração da Páscoa na sede do Chabad na Tailândia, e acrescenta que no Séder ${ }^{10}$ de 2001 os rabinos do Chabad e seus seguidores conduziram quase 9.000 ceias públicas da Páscoa judaica em 23 regiões do mundo, servindo mais de meio milhão de refeições. Lugares recônditos da África (as montanhas Atlas do Marrocos), da Ásia (Bangkok, Hanói, Pequim e Katmandu) e da América Latina (Belém do Pará e cidades interioranas, Cochabamba e Pucón) são alvos do Chabad, que não só procura judeus residentes do lugar, mas, também, mochileiros israelenses que, liberados do exército, costumam fazer longas viagens ao Oriente ou à América Latina.

As estratégias do movimento Chabad também incluem a criação de escolas, colégios, academias rabínicas, espaços de estudos informais, sinagogas, supervisão de alimentos kasher ${ }^{11}$ para o consumo dos judeus observantes, passeios de final de semana e uma gama muito variada de cursos e palestras para todos aqueles interessados em conhecer alguma dimensão do judaísmo (TOPEL, 2005). Bibliotecas com livros judaicos e publicação de revistas e newsletters são outras

\footnotetext{
${ }^{9}$ Do hebraico: pl. de mitzvá: mandamento, preceito.

${ }^{10}$ Do hebraico: ordem. O termo designa a ceia festiva celebrada durante Pessach, usualmente identificada como Páscoa judaica.

${ }^{11}$ Do hebraico: idôneo, apto, em referência aos alimentos permitidos para o consumo dos judeus ortodoxos.
}

Cad. de Pesq. Interdisc. em Ci-s. Hum-s., Florianópolis, v.13, n.103, p.79-91, ago/dez 2012 
formas de divulgar a doutrina do Chabad. É importante, também, mencionar a gigantesca editora Kehot Publication Society que tem sede em vários países e cujos livros, vendidos a preços ínfimos ou oferecidos de graça, são continuamente traduzidos para mais de doze línguas.

Nos Estados Unidos, centro do Chabad e país que tem a maior comunidade judaica do mundo, existem mais de cem campi universitários que contam com a presença constante de emissários do Rebe.

No que diz respeito à internet, além do mega-site Chabad.org, encontramos sites de emissários do Chabad em cada uma das cidades nas quais há representantes do movimento. Neles, o internauta se depara com diversas informações: a história do movimento e de suas lideranças, lições de Torá e Talmud, explicações sobre o calendário judaico, prédicas de rabinos, além de informes sobre as atividades daquele centro específico. A clássica seção "pergunte ao rabino" é um instrumento que permite a criação de comunidades virtuais de membros e curiosos interessados em discutir diferentes tópicos do judaísmo, e uma janela para o início do processo de conversão ao judaísmo ortodoxo.

Como faz questão de destacar Pinto, numa revista do movimento Chabad (2006, p. 4), na atualidade presenciamos um renascimento do judaísmo que deve sua existência à internet, acrescentando: "judeus que desejam sentirem-se judeus na mais remota aldeia da Ucrânia ou na menor das cidadezinhas italianas, ambas privadas de um rabino, podem, agora, pertencer à família judaica”. Talvez seja mais preciso afirmar que o que estamos presenciando é uma reconfiguração do judaísmo ou, até, o surgimento de um novo judaísmo.

\section{A transnacionalização da ortodoxia judaica e a revalorização do espaço diaspórico: um paradoxo?}

No que diz respeito ao judaísmo, pode se mencionar o movimento Chabad como exemplo emblemático do processo de transnacionalização da religião judia, já que, a partir de seu centro nos Estados Unidos, tem se propagado pelo globo, desenvolvendo complexas redes de relações entre esse centro e as diásporas; entre diásporas centrais e periféricas; e, finalmente, entre os Estados Unidos, as diversas diásporas e o Estado de Israel. Além do mais, há indícios de que o Chabad tem 
explodido, se assim posso me expressar, a dicotomia Israel/Exílio ao fundar um novo centro judaico: a casa do Rebe em 770 Eastern Parkway.

O caso judeu é uma expressão nítida do processo de transnacionalização da religião que vemos se propagar nos dias de hoje, em um panorama marcado pela diversidade do campo religioso que rejeita a estandardização ou homogeneização revelando as múltiplas formas em que se combinam e negociam o global e o local.

O transnacionalismo que caracteriza o Chabad não se expressa unicamente através da sua vasta rede institucional encontrada em mais de 70 países e na grande quantidade de sites, blogs, comunidades virtuais e outros, senão na própria trajetória de seus emissários e no público que, em algumas regiões, é o alvo do Chabad: o homem de negócios sem endereço fixo ou com múltiplos endereços - o homem transnacional. Xun (2011, p. 127) menciona que entre 2.000 e 3.000 executivos judeus passam anualmente por Pequim e que o Centro Chabad estabelecido nessa cidade serve para eles como "um lar longe do lar", sendo que em muitos casos lhes permite reconectar-se ou conectar-se com suas raízes judaicas.

Paralelamente, é comum encontrar em uma família de emissários do Chabad, ou de seus adeptos, diferentes lugares de residência dos diversos membros da família. No seu instigante artigo sobre a entrada do Chabad em Pequim, Xun (2011) menciona que o rabino destinado a criar a nova comunidade nessa cidade chinesa nasceu na África do Sul, educou-se e foi ordenado rabino no Brooklyn, anos mais tarde partiu rumo a Hong Kong e depois à China para estabelecer um centro Chabad na capital do país. No Brasil, como em outros contextos nacionais, assistimos ao mesmo cenário: famílias de origens diversas que fincaram residência em alguma cidade brasileira, mas que têm filhos estudando ou atuando como emissários do Rebe em outros países. A minha experiência etnográfica com os judeus ortodoxos de São Paulo e a bibliografia sobre a ortodoxia judaica em outros espaços permite esboçar a hipótese de que o mandato endogâmico e o shiduch (arranjo matrimonial) constitui outra estratégia de expansão do movimento, na medida em que os casamentos entre pessoas de diferentes países é a praxe e não uma exceção.

Mas se o transnacionalismo do movimento Chabad é um traço facilmente observável, o que chama a atenção é a reconfiguração dos espaços sagrados judaicos milenares que tal processo desencadeou. Dito de outro modo, percebe-se o deslocamento de Jerusalém como axis mundi para Crown Heights em 770 Eastern 
Parkway e, em menor grau, para todas as cidades nas quais existe uma sinagoga Chabad.

No intuito de compreender melhor esta hipótese, é importante mencionar que apesar do povo judeu constituir o exemplo histórico por excelência do conceito de diáspora, fenômenos como a transnacionalização, a pós-modernidade, a dessionização, o pós-sionismo e a globalização mudaram o padrão das comunidades judaicas, as suas inter-relações e as relações com o centro e com Israel (SAFRAN, 1991; 2005; BAUMAN, 2000; COHEN, 1997; 2008; SORJ, 2004). Além do mais, diversos fenômenos políticos e sociais ocorridos nas últimas décadas levaram a que alguns estudiosos do judaísmo reintroduzissem de um modo inovador o conceito de diáspora na reflexão sobre o judaísmo e as comunidades judaicas. O objetivo dessa nova abordagem é salientar as conotações positivas da diáspora vis-à-vis com a centralidade que, a partir da sua fundação, o Estado de Israel teve para os judeus do mundo inteiro (BOYARIN; BOYARIN, 1993; STEINER, 1998; RAPPORT, 2002; SAFRAN, 2005; COHEN, 2008; SORJ, 2010). Assim, por exemplo, Sorj (2010, p. 110) é assertivo quando afirma que a revalorização de identidades transnacionais e o processo de globalização, a que se soma o sucesso de uma diáspora judaica livre de perseguições, recolocam o Estado de Israel e a diáspora numa perspectiva nova e diferente.

Nesse sentido, novas pesquisas (GUREVITCH; ARAN, 1994) revelam que a diáspora e o exílio, concebidos como transitórios e como castigo - do modo em que essa formulação se encontra na cosmologia judaica - não têm sido a forma na qual, de fato, as comunidades judaicas se relacionaram com o espaço em sua longa história diaspórica. Muito pelo contrário, essas pesquisas demonstram o papel central do território nas diversas e variadas comunidades judaicas da diáspora, espaços que têm sido incorporados como territórios próprios do grupo e, inclusive, sacralizados. Mitos de origem em diferentes regiões do globo nas quais houve ou há comunidades judaicas pareceriam ser mais comuns do que o postulado pelas diretrizes de uma história judaica influenciada pela cosmologia judaica primeiro e, posteriormente, pela ideologia sionista expressa no pressuposto da negação do exílio (shlilat ha'galut).

No que diz respeito ao movimento Chabad, as peregrinações de judeus do mundo inteiro ao que era a casa do Rebe e, depois de sua morte, a seu túmulo, de algum modo evocam as peregrinações dos judeus a Jerusalém ao longo dos 
séculos. Goldschmidt (2000, p. 85) vai além e afirma que em um movimento oposto ao que presenciamos na contemporaneidade (a condição de desterritorialização de diferentes segmentos da população mundial como consequência do aumento das novas diásporas), no caso do Chabad observa-se uma reterritorialização da diáspora judaica em Crown Heights: através das peregrinações multitudinárias mencionadas, dos encontros dos emissários do Rebe todo mês de novembro nesse lugar e nas ruas contíguas, que transformaram uma parte significativa do bairro num bairro do Chabad, os adeptos do Rebe lutam por reforçar as fronteiras comunais e controlar a dispersão da identidade do grupo. Como lucidamente observa Goldschmidt (2000, p. 85), "eles [os membros do movimento Chabad] tendem a imaginar um judaísmo solidificado numa pedra - como as Tábuas da Lei - inclusive na diaspórica Crown Heights".

Por último, tendo em consideração as análises desenvolvidas, parece-me que um dos fenômenos inovadores, que trouxe o Chabad ao judaísmo, é a legitimação de crenças populares do passado, que enxergavam uma "Nova Jerusalém" nos lugares nos quais existia um Grande Rabino (GREEN, 1977). 


\section{REFERÊNCIAS}

BAUMAN, M. Diáspora, genealogies of semantics and transcultural comparison. In: Numen, 47(3), 2000.

BOYARIN, D.; BOYARIN, J. Diasporas: Generation and the Ground of Jewish Identity. In: Critical Inquiry, 19, 1993.

CASTELLS, M. A Era da Informação: Economia, Sociedade e Cultura. Vol. 2: O poder da Identidade. São Paulo: Paz e Terra, 1999.

COHEN, R. Global Diasporas: an introduction. Nova lorque: University of Columbia Press, 1997.

COHEN, R. Sólidas, dúcteis e líquidas: noções em mutação de "lar" e "terra natal" nos estudos da diáspora. In: CADERNO CRH, 21(54), 2008.

ELIOR, R. The Lubavitch Messianic Resurgence: The Historical and Mystical Background 1939-1996. In: SCHÄFER, P. \& COHEN, M. (eds): Towards the Millenium: Messianic Expectations from the Bible to Waco. Leiden: Brill, 1998.

FESTINGER, L; RIECKEN, E.; SCHACHTER. S. (orgs). When Prophecy Fails. New York: Harper Torchbooks, 1964.

FISHKOFF, S. The Rebbe's Army: Inside the World of Chabad-Lubavitch. New York: Schoken Books, 2003.

GOLDSCHMIDT, H. Crown Heights is the Center of the World: Reterritorializing a Jewish Diaspora. In: Diaspora, 9(1), 2000.

GREEN, A. The Zaddiq as Axis Mundi in Later Judaism. In: JAAR, 3, 1977.

GUREVITCH, Z.; ARAN, G. Never in place: Eliade and Judaic sacred space. In: Archives de Sciencies Sociales des Religions, 87, 1994. 
HEILMAN, S.; FRIEDMAN, M. The Rebbe: The Life and Afterlife of Menachem Mendel Schneerson. Princeton: Princeton University Press, 2010.

PACE, E. Religião e Globalização. In: ORO, A. P. \& STEIL, C. A. Globalização e Religião. Petrópolis: Vozes, 1997.

PINTO, D. Globalization and the Rebirth of European Jewry. In: SHMA, A Journal of Jewish Responsibility. Jewish Family \& Life (JFL Media). January 2006: 4-5.

Disponível em: <http://www.bipa.org/Publications/details.cfm?Publication|D=6382>. Acesso em: 18 jun. 2011.

SAFRAN, W. Diasporas in Modern Societies: Myths of Homeland and Return. In: Diaspora, 1(1), 1991.

SAFRAN, W. The Jewish Diaspora in a Comparative and Theoretical Perspective. In: Israel Studies, 10(1), 2005.

SORJ, B. Diáspora, Judaísmo e Teoria Social. In: GRIN, M.; VIEIRA, N. H. (orgs). Experiência cultural judaica no Brasil. Rio de Janeiro: Topbooks, 2004.

SORJ, B. Judaísmo para todos. Rio de Janeiro: Civilização Brasileira, 2010.

STEINER, G. War, Terrorism and Chaos: God's Idea of Keeping a Promise. In: The Observer Review, February 22, 1998.

RAPPORT, N. Em louvor do cosmopolita irônico: Nacionalismo, o "judeu errante" e a cidade pós-nacional. In: Revista de Antropologia, 45(1), 2002.

TOPEL, M. Jerusalém \& São Paulo: a nova ortodoxia judaica em cena. Rio de Janeiro: Topbooks, 2005.

XUN, Z. Mikvah in Beijing. In: European Review of History, 18(1), 2011.

Artigo:

Recebido em: 18/11/2012

Aceito em: 23/12/2012 